This item was submitted to Loughborough's Research Repository by the author.

Items in Figshare are protected by copyright, with all rights reserved, unless otherwise indicated.

\title{
Exploration of matrix effects in laser ablation inductively coupled plasma mass spectrometry imaging of cisplatin treated tumors
}

\section{PLEASE CITE THE PUBLISHED VERSION}

https://doi.org/10.1021/acs.analchem.0c01347

\section{PUBLISHER}

American Chemical Society

\section{VERSION}

AM (Accepted Manuscript)

\section{PUBLISHER STATEMENT}

This document is the Accepted Manuscript version of a Published Work that appeared in final form in Analytical Chemistry, copyright $\odot$ American Chemical Society after peer review and technical editing by the publisher. To access the final edited and published work see https://pubs.acs.org/doi/10.1021/acs.analchem.0c01347.

\section{LICENCE}

CC BY-NC-ND 4.0

\section{REPOSITORY RECORD}

Greenhalgh, Calum, Ellie Karekla, Gareth J Miles, Ian R Powley, Catia Costa, Janella de Jesus, Melanie Jane Bailey, et al.. 2020. "Exploration of Matrix Effects in Laser Ablation Inductively Coupled Plasma Mass Spectrometry Imaging of Cisplatin Treated Tumors". Loughborough University. https://hdl.handle.net/2134/12555839.v1. 


\title{
Exploration of Matrix Effects in Laser Ablation Inductively Coupled Plasma Mass Spectrometry Imaging of Cisplatin Treated Tumours
}

\author{
Calum J. Greenhalgh $\uparrow$ Ellie Karekla, $\ddagger$ Gareth J. Miles, $\uparrow$ Ian R. Powley, $\ddagger$ Catia Costa, $\neq$ Janella de Jesus, $\|$ \\ Melanie J. Bailey,\| Catrin Pritchard, \$ Marion MacFarlane, $\S$ J. Howard Pringle $\ddagger$ and Amy J. Managh †* \\ $\dagger$ Department of Chemistry, Loughborough University, Loughborough, Leicestershire, LE11 3TU, UK. *E-mail: \\ A.J.Managh@lboro.ac.uk \\ $\$$ Leicester Cancer Research Centre, University of Leicester, Robert Kilpatrick Building, Leicester Royal Infirmary, Leices- \\ ter, LE2 7LX, UK.
}

¥ Ion Beam Centre, University of Surrey, Guildford, GU2 7XH, UK.

$\|$ Department of Chemistry, University of Surrey, Guildford, GU2 7XH, UK.

§ MRC Toxicology Unit, University of Cambridge, Hodgkin Building, Leicester, LE1 9HN, UK.

\begin{abstract}
The use of a low aerosol dispersion ablation chamber within a LA-ICP-MS set up allows for high-resolution, highspeed imaging of the distribution of elements within a sample. Here we show how this enhanced capability creates new analytical problems and solutions. We report the distribution of platinum at the cellular level in non-small cell lung cancer (NSCLC) explant models after treatment with clinically relevant doses of cisplatin. This revealed for the first time a correlation between the platinum signal and the presence of carbon deposits within lung tissue. We show how complementary ion beam analysis techniques, particle induced X-ray emission (PIXE) and elastic backscattering spectrometry (EBS) can be used to explore potential matrix effects in LA-ICP-MS data. For these samples, it was confirmed that the enhancement was unlikely to have resulted from a matrix effect alone. Thus, the presence of carbon deposits within tissue has potential implications for the effective distribution of the cisplatin drug.
\end{abstract}

Cisplatin is a part of a family of platinum based chemotherapeutic drugs whose mechanism of action is to form platinum adducts with DNA. This creates inter- and intra- strand cross links that prevent further DNA replication and eventually lead to apoptosis. ${ }^{1}$ Cisplatin is used in the treatment of solid tumours such as nonsmall cell lung cancer (NSCLC) and the use of cisplatin in combination therapy for the treatment of NSCLC provides only $5.4 \%$ of patients with a 5 -year survival benefit. ${ }^{2}$ This is often due to tumours exhibiting resistant properties that prevent effective penetration of the drug within the tissue. ${ }^{3}$ Not exclusive to NSCLC, the difficulties surrounding cisplatin resistance mean that prescreening tests are essential to predicting the benefit of cisplatin therapies before they are used. Typical prescreening approaches for drug resistance include the use of 2D cell-based assays, patient derived xenograft mouse models and multicellular tumour spheroids. ${ }^{4-7}$ These each have drawbacks, such as the unrepresentative conditions monolayer cultures grow under, expense and the length of time taken to complete. An alternative model, $3 \mathrm{D}$ ex vivo human tissue culture, has been previously demonstrated to be a reliable and low-cost technique for the modelling of tumour-drug responses. ${ }^{8,9}$

To assess therapeutic response within the models, understanding the distribution of the drug within the tissue is essential. Laser ablation inductively coupled plasma mass spectrometry (LA-ICPMS) is a technique that can provide highly spatially resolved analysis of elemental distribution within a sample. It has been used for a broad range of bioimaging applications involving endogenous metals and metallodrug distribution, with Pozebon et $a l^{I 0}$ providing a comprehensive but non-exhaustive list of pub- lished work. Platinum-based drug imaging has been performed using LA-ICP-MS within a range of biological systems including mouse and rat organs, ${ }^{11-16}$ human colorectal tumours, ${ }^{17}$ lung tumours, ${ }^{18}$ muscle ${ }^{19}$ and hair. ${ }^{20}$

LA-ICP-MS imaging of tumour spheroids and ex vivo explant cultures has been used to help improve the predicting power of pre-clinical drug screening. Niehoff et $a l^{21}$ used down to $5 \mu \mathrm{m}$ resolution to image TFK-1 spheroids dosed with mTHPP-Pd and cisplatin. Theiner et al, ${ }^{5}$ imaged the distribution of three platinum based compounds within ovarian teratocarcinoma and colon carcinoma spheroid models. In a recent study using ex-vivo explant tissue, Karekla et al linked cisplatin sensitivity to the distribution of the drug across the tissue. ${ }^{8}$ In cisplatin resistant tissue, platinum was preferentially found outside of tumourigenic areas, while in cisplatin sensitive cases, the drug distribution was more homogenous across the tumour and stroma. While having provided greater understanding of platinum drug movement, metabolism and toxicity, the research has been limited by the resolution and speed of analysis achievable by older LA designs, with typical resolutions ranging between 5 and $100 \mu \mathrm{m} .^{22}$ Higher resolution is an important factor when analyzing biological materials as the heterogenous nature of these samples is more accurately revealed by the greater number of laterally resolved pixels generated using a smaller laser spot size. A drive to improve ablation cells within LA systems has led to low aerosol dispersion designs with pulse response durations reaching below $10 \mathrm{~ms}^{23-25}$ compared to older designs where $500 \mathrm{~ms}$ was typical. ${ }^{26}$ The modern systems minimize the dispersion of ablated material by using optimized cell and transport geometries to efficiently capture the generated aero- 
sol and deliver it to the to the ICP. ${ }^{26}$ Greater control of the aerosol plume also facilitates improved absolute sensitivity of the analysis. ${ }^{23,27}$ These factors have led to dramatic increases in the speed and lateral resolution of analysis, making LA-ICP-MS a more viable technique for screening tests.

Since the emergence of low dispersion cell designs in the last 5 years, a small number of examples have been published that demonstrate the use of these systems to image platinum containing drugs at a sub-cellular level. Van Acker et $a l^{28}$ used $1 \mu \mathrm{m}$ laser spot sizes to quantify cisplatin distribution across kidney sections of Cynomolgus monkeys, with higher Pt signals corresponding to areas associated with the reuptake of cisplatin after it has been metabolized and filtered from the blood. Theiner et $a l^{29}$ demonstrated imaging of oxaliplatin within tumour spheroids with a resolution down to $2.5 \mu \mathrm{m}$ using deconvolution algorithms. However, imaging of lung tissue at high resolution presents an additional analytical challenge due to the presence of inhaled carbon particles, which are not present in these other tissues.

In the present work, LA-ICP-MS imaging of a 3D ex vivo human explant model using a $2 \mu \mathrm{m}$ laser spot size is reported, revealing for the first time a spatial correlation between platinum and carbon deposits in lung tissue. ICP-MS approaches rely on ionization of a target atom for detection. Depending on the sample matrix, ion formation can be suppressed or enhanced. This can lead to imaging artefacts if the sample matrix changes substantially across the imaged area. We propose a novel orthogonal analytical approach to verify the LA-ICP-MS elemental mapping data. Ion beam analysis (IBA) is a suite of techniques that do not suffer from ion suppression effects. ${ }^{30}$ IBA has been used in many previous studies of tissues and cells, for example to study Pt distribution in cells. ${ }^{31}$ For the IBA technique particle induced X-ray Emission (PIXE), elements are detected via X-rays emitted from inner shell electrons, so PIXE is insensitive to the sample chemistry. The X-ray intensity can be reduced when the average $\mathrm{Z}$ of the sample changes, due to absorption and fluorescence of X-rays upon their exit path. We show here how Rutherford backscattering spectra, collected simultaneously with X-ray data, allows the matrix composition of a sample to be independently monitored. Through application of our orthogonal imaging approach, we demonstrate that high resolution imaging using a low dispersion cell design reveals the importance of small-scale features in the tissue. These features were overlooked in earlier studies, and are pertinent to effective distribution of the drug in humans.

\section{EXPERIMENTAL}

3D ex vivo explant culture. NSCLC explants were prepared according to the protocols described previously. ${ }^{8}$ Briefly; NSCLC tumours were collected from patients undergoing surgery (ethical approval: LREC: 07/MRE08/ 07). Haematoxylin and eosin (H\&E) staining was used to identify viable sections before tissue fragments sized 2 to $3 \mathrm{~mm}^{3}$ were cultured for 16 to 20 hours. Samples were then incubated with $0-50 \mu \mathrm{mol} / \mathrm{L}$ cisplatin for 24 hours before being embedded in paraffin blocks and sectioned at $4 \mu \mathrm{m}$ thickness.

Histological analysis. Histological analysis was performed as described previously. ${ }^{8}$ Briefly: On serial sections, H\&E staining was performed as well as immunohistochemistry (IHC) using cleaved PARP Clone E51 and Ki67 Clone MIB-1 antibodies. The stained slides were scanned and digitally converted into virtual slides using a whole slide scanner (Hamamatsu Nanozoomer XR, Welwyn Garden City, UK). ${ }^{32}$ Viewing and analyzing the virtual slides was done by using the NDP.View29 (Hamamatsu) and tumour areas in the H\&E stained images were outlined using QuPath image analysis software. ${ }^{33}$
Gelatine preparation. A gelatine solution (Type B from bovine skin, Sigma Aldrich) was prepared gravimetrically with $18 \mathrm{MM}$ water to a concentration of $10 \%(\mathrm{w} / \mathrm{v})$. The gelatine was heated at $65^{\circ} \mathrm{C}$ with mixing every 20 minutes until completely dissolved. Aliquots were spiked with a $50 \mu \mathrm{g} / \mathrm{ml}$ platinum standard (SCP Science, Quebec, Canada) and/or $1 \mathrm{mg} / \mathrm{ml}$ finely ground charcoal powder (Sigma-Aldrich, UK) and allowed to incubate at $65^{\circ} \mathrm{C}$ for 24 hours. $10 \mu \mathrm{L}$ gelatin droplets were dispensed onto glass microscope slides, preheated to $95^{\circ} \mathrm{C}$, for LA-ICP-MS imaging, or polyethylene terephthalate (PET) slides for ion beam analysis. These large ( $2.5 \mathrm{~mm}$ diameter) droplets were used to investigate matrix effects during the ablation process.

Piezoelectric generated droplets. To investigate matrix effects at the ionization stage, a series of smaller droplet standards were prepared using an approach adapted from a method recently reported by Arakawa et al. ${ }^{34}$ Picolitre droplets were produced using a MD-E-30xx piezoelectric droplet generation system (Microdrop Technologies GmbH, Norderstedt, Germany), fitted with a MDK0130-20 dispenser head, with a $50 \mu \mathrm{m}$ nozzle. A voltage of 107 $\mathrm{V}$, with a $29 \mu$ s pulse width at a frequency of $1 \mathrm{~Hz}$ was used dispense droplets of $\sim 14 \mathrm{pL}$ in volume. Aqueous droplets containing $10 \mathrm{ppm}$ platinum with either $0,10,100$ or 500 ppm carbon (Inorganic Ventures, Christiansburg, USA) were dispensed onto a microscope slide that was pre-coated with a thin layer of gelatine. The gelatine solution is too viscous to pass through the small nozzle of the droplet generator, thus pre-coating the slide with gelatine was used instead as an attempt to provide a matrix match to the samples. A computer controlled $\mathrm{x}, \mathrm{y}$ stage was used to position the target beneath the droplet generator, enabling grid patterns of droplets to be printed. Post analysis, the total ${ }^{195} \mathrm{Pt}$ signal from individual droplets was integrated and an average of the total counts for 3 repeats at each carbon concentration was reported.

Laser ablation inductively coupled plasma mass spectrometry. Analysis was performed using an NWRImage 266nm laser ablation system (Elemental Scientific Lasers, Bozeman, Montana), coupled to an Element XR sector-field ICP-MS (Thermo Scientific, Bremen, Germany). The laser ablation system was equipped with a low-dispersion cell within the standard TwoVol2 chamber and a Dual Concentric Injector, to produce fast transient signals of $\sim 10 \mathrm{~ms}$ duration (see Supporting Information). A laser spot size of $2 \mu \mathrm{m}$ diameter, $100 \mathrm{~Hz}$ repetition frequency, $200 \mu \mathrm{m} \mathrm{s}^{-1}$ scan speed and fluence of $\sim 18 \mathrm{~J} \mathrm{~cm}^{-2}$ were used to perform the sampling. Ablation lines were parallel to each other with no gaps left between ablated lines. These conditions were chosen to avoid overlapping craters, i.e. a consecutive fresh location was sampled with each laser shot. The laser was allowed to warm up for 2 seconds before each line and washout for 2 seconds after each line. A helium carrier gas flow of $\sim 1.4 \mathrm{~L} \mathrm{~min}^{-1}$ was used. ICP-MS parameters were as follows; radio frequency power of $1100 \mathrm{~W}$, Ar carrier gas flow of $0.50 \mathrm{~L} \mathrm{~min} \mathrm{~m}^{-1}$, Ar auxiliary flow of $0.9 \mathrm{~L} \mathrm{~min} \mathrm{~m}^{-1}$, Ar plasma gas flow of $15.75 \mathrm{~L} \mathrm{~min}^{-1}$. The monitored isotope ${ }^{195} \mathrm{Pt}$, was measured in low mass resolution mode $(\mathrm{R}=300)$ with the detector in counting mode. To collect data from the ICP-MS a P7882 photon counter board (FAST ComTec GmbH, Oberhaching, Germany) was connected to the ion detection board and monitored using MCDWIN software, as previously described, ${ }^{35}$ which allowed for blind time free collection of data with a $10 \mathrm{~ms}$ dwell time. Image generation was performed using in-house software; LA-ICP-MS ImageTool v1.7 (Reid-IT limited, Loughborough, UK) ${ }^{36}$ with final production of the graphics performed using DPlot (Hydesoft Computing, LLC, USA).

Ion Beam Analysis (IBA). Ion beam analysis of gelatine droplets was performed using the microbeam line on the $2 \mathrm{MV}$ Tandetron accelerator (HVEE Corporation, NL) installed in the Stephens Laboratory of the University of Surrey Ion Beam Centre. Measurements were carried out using a $2.5 \mathrm{MeV}$ proton beam focused 
to a diameter of $2 \mu \mathrm{m}$ with a current of $i 700 \mathrm{pA}$. Proton induced $\mathrm{X}$-rays (PIXE) were detected using a lithium drifted silicon detector (SGX Sensortech, UK). The X-ray detector was fitted with a $130 \mu \mathrm{m}$ beryllium foil to stop backscattered protons from entering the detector and causing spectrum degradation. Elastically backscattered protons (EBS) were detected using a passivated implanted planar silicon charged particle detector (Canberra, now
Mirion Technologies, USA) with an active area of $300 \mathrm{~mm}^{2}$. The $\mathrm{X}$-ray detector efficiency with energy was calibrated at the start of the run through the analysis of a lead-glass standard reference material (BCR-126A, European Commission, Joint Research Centre (JRC), Geel, Belgium). OMDAQ 3 (Oxford Microbeams Ltd., UK) software was used to collect and process the spectral data.
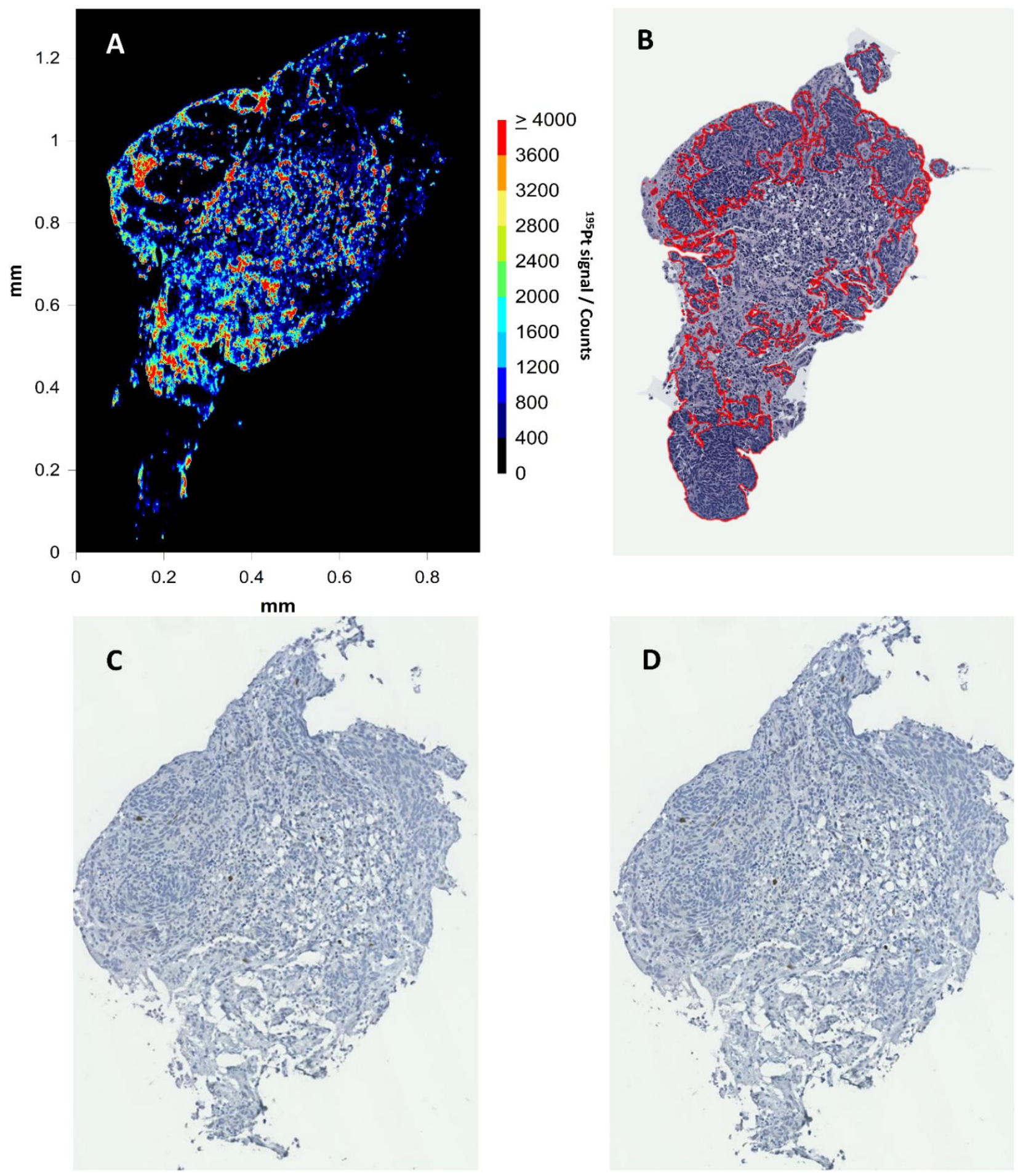

Figure 1. Image A displays the cisplatin distribution found in the cisplatin resistant explant dosed with $50 \mu \mathrm{M}$ cisplatin. B displays H\&E staining, with the tumour areas outlined in red, while C and D demonstrate Ki67 and cPARP immunohistochemistry respectively. ${ }^{195} \mathrm{Pt}$ was monitored to produce the cisplatin profile. Within figure $\mathrm{A}$ the $\mathrm{X}$ and $\mathrm{Y}$ axis offer dimensions for the ablated section and the $\mathrm{Z}$ axis represents the platinum signal in total counts for each pixel generated in the image. 

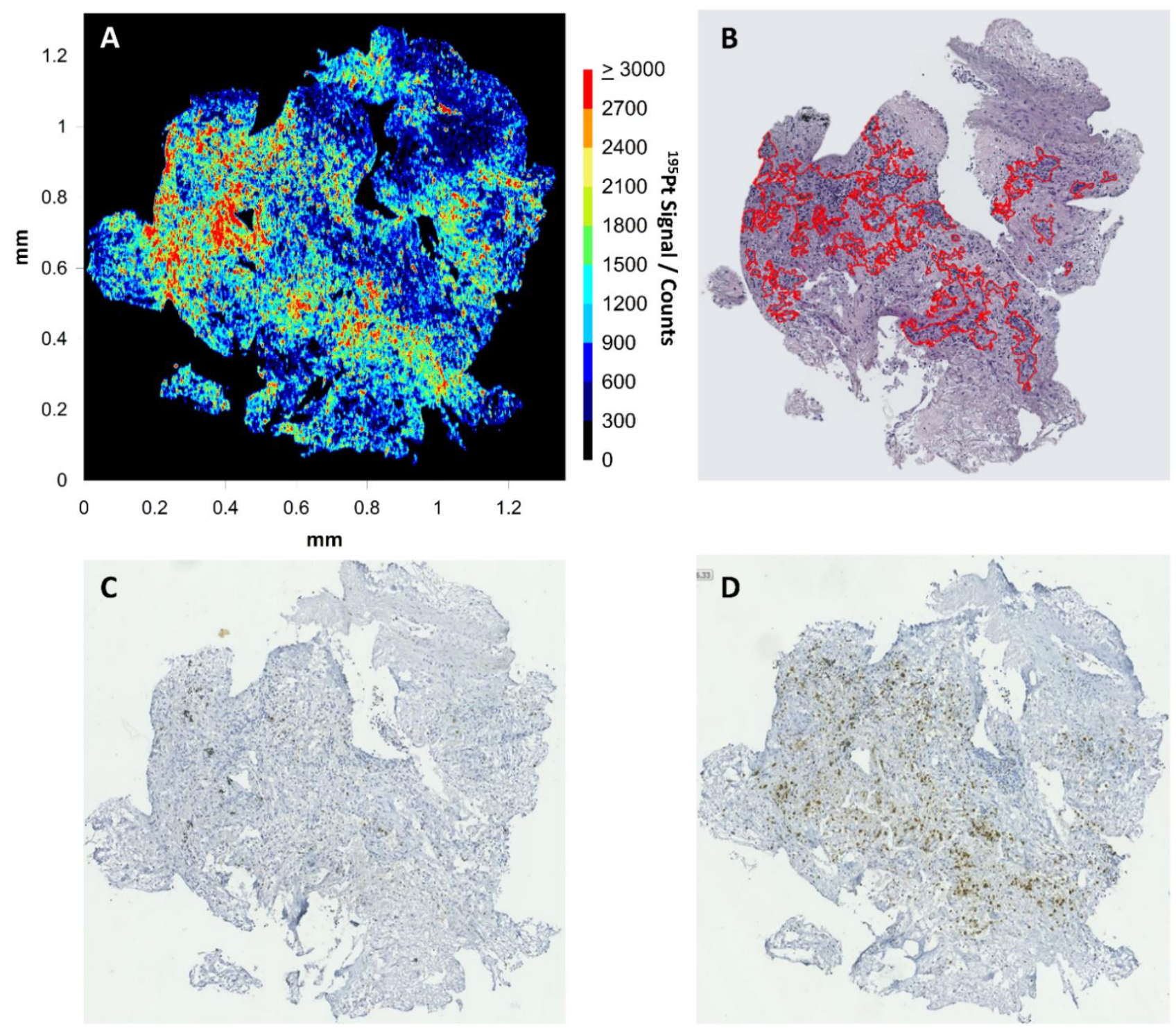

Figure 2. Image A displays the cisplatin distribution found in a sensitive, dose dependent explant dosed with $50 \mu \mathrm{M}$ cisplatin. B displays H\&E staining, with the tumour areas outlined in red, while C and D demonstrate Ki67 and cPARP immunohistochemistry respectively. ${ }^{195} \mathrm{Pt}$ was monitored to produce the cisplatin profile. Within figure $\mathrm{A}$ the $\mathrm{X}$ and $\mathrm{Y}$ axis offer dimensions for the ablated section and the $\mathrm{Z}$ axis represents the platinum signal in total counts for each pixel generated in the image.

\section{RESULTS AND DISCUSSION}

Comparison of LA-ICP-MS and histology data. The use of a low dispersion ablation cell and Dual Concentric Injector (DCI) facilitated high speed imaging of the explant tissue. A variety of approaches to provide imaging at high resolution have previously been reported, including the use of "oversampling" to quantitatively drill through each section, followed by deconvolution of the data $^{25}$ or "super resolution reconstruction", 37 where offset orthogonal acquisitions across a sample are combined. Here, a $2 \mu \mathrm{m}$ spot and a pixel-by-pixel imaging approach were used to enable detailed comparison with serial histological sections at subcellular resolution.

H\&E staining was used to identify the cellular distribution of tumour and stromal cells, while Ki67 and cleaved PARP (cPARP) antibodies were used to identify regions of high proliferation and cell death respectively. All three stains were used to assess and identify the response of tumour and stromal cell areas to cisplatin. Ki67 and cPARP activity was determined by the intensity of dark brown, IHC positive, staining across the sections. Explant tissues were previously categorized as either cisplatin sensitive or cisplatin resistant according to their response to cisplatin treatment. ${ }^{8} \mathrm{~A}$ third category known as dose dependent resistant was based upon the dose dependent induction of TP53 expression as identified in the previous work. ${ }^{8}$ In all cases as cisplatin dose was increased, the total platinum ion intensity in the section increased, regardless of the tissue's phenotype. Formalin fixation and paraffin embedding is the gold standard for preparing tissue for clinical diagnostics and has been used for several cisplatin imaging studies. ${ }^{12,28}$ It has been previously observed that alkaline metals can be leached from the tissue during this process, but this is not noted for transition metals, such as platinum. ${ }^{38}$ It was suggested that leaching varies based upon the location and strength of binding within the biological sample. The therapeutic action of cisplatin is through binding to DNA within the nucleus or in some cases protein structures in organelles, ${ }^{39}$ thus leaching affects are expected to be minimal in these samples. 
Cisplatin resistant explants (Figure 1 and Supporting Information), demonstrated a distinct pattern of cisplatin distribution when compared to the histology. Very low levels of platinum were found in areas associated with a high density of tumour cells, as identified by the H\&E staining. The highest levels of platinum were present in areas with stromal cells and connective tissue with comparatively lower levels of tumour cells. A similar distribution was observed at all three cisplatin doses but appeared to be less apparent in the $50 \mu \mathrm{M}$ sample. This is most likely due to a saturation effect where higher doses of cisplatin are forced to move to other areas of the tissue. There was a low level of cPARP activity in all three samples that can be attributed to the ineffective nature with which the cisplatin penetrates the tissue in resistant cases and therefore has not induced cell death mechanisms in these samples.

Throughout the sensitive and dose dependent explants the overall distribution of cisplatin is more homogenous than in the resistant samples (Figure 2 and Supporting Information). Although in the $1 \mu \mathrm{M}$ samples (Figure 3 and Supporting Information), platinum accumulation was preferentially found in some areas of stroma, similar to the resistant samples. As the dose increased, preferential accumulation was found in regions of tumour cells as shown by the H\&E staining. In the $50 \mu \mathrm{M}$ dose dependent sample very high cPARP activity was found in locations demonstrating preferential accumulation of cisplatin. This links with the previous reported findings that at higher doses of cisplatin, TP53 induced cell death was greater and displayed higher levels of cPARP activity. Ki67 activity is also low in this sample which is most likely due to the effective penetration of cisplatin, which prevents replication. The marked differences in cPARP activity between sensitive and resistant explants are likely to be due to the ability of cisplatin to effectively penetrate the tumour cells in the sensitive samples.

Effect of carbon deposition. Carbon deposits, characterized by clusters of black dots, were visible in the histological sections of some explants. In each case, high platinum signals were associated with the regions containing carbon deposits, which was confirmed by analyzing a sample that contained a very large region of deposition (Figure 3). The relationship between carbon deposits and platinum distribution was overlooked in the previous study of this explant model. It is probable that the large laser spot size used in the earlier work $(10 \times 5 \mu \mathrm{m}$ compared to $2 \times 2 \mu \mathrm{m}$ here $)$ smeared out the appearance of these small features. The effect was also not reported in prior studies that used an alternative, tumour spheroid model. Laboratory created tumours may not account for the full range of factors that patient lung tissue will have been exposed to, which serves to highlight the importance of the continued availability of ex-vivo tissue for cancer research.

The presence of carbonaceous particulate matter in lung tissue has been associated with inhalation of cigarette smoke and environmental exposure to traffic exhaust fumes. ${ }^{40}$ Hence, one hypothesis was that the platinum in the carbon deposits could originate from exposure to catalytic converters, which typically contain platinum and release platinum containing particulate into the environment at reported rates of up to $313 \mathrm{ng} \mathrm{km}^{-1}{ }^{41,42}$ Despite this, subsequent analysis of palladium and rhodium, two other common elements found in catalytic converters, produced no noticeable signature (Supporting Information). The carbon association effect was also investigated using control samples that had received treatment with the DMF carrier only; one containing noticeable carbon deposits and another without.

The Pt signal detected in these control samples was very low, with only a faint outline of the shape of the section visible (Supporting Information). No significant enhancement of Pt signal was associated with the carbon deposits in these samples, which
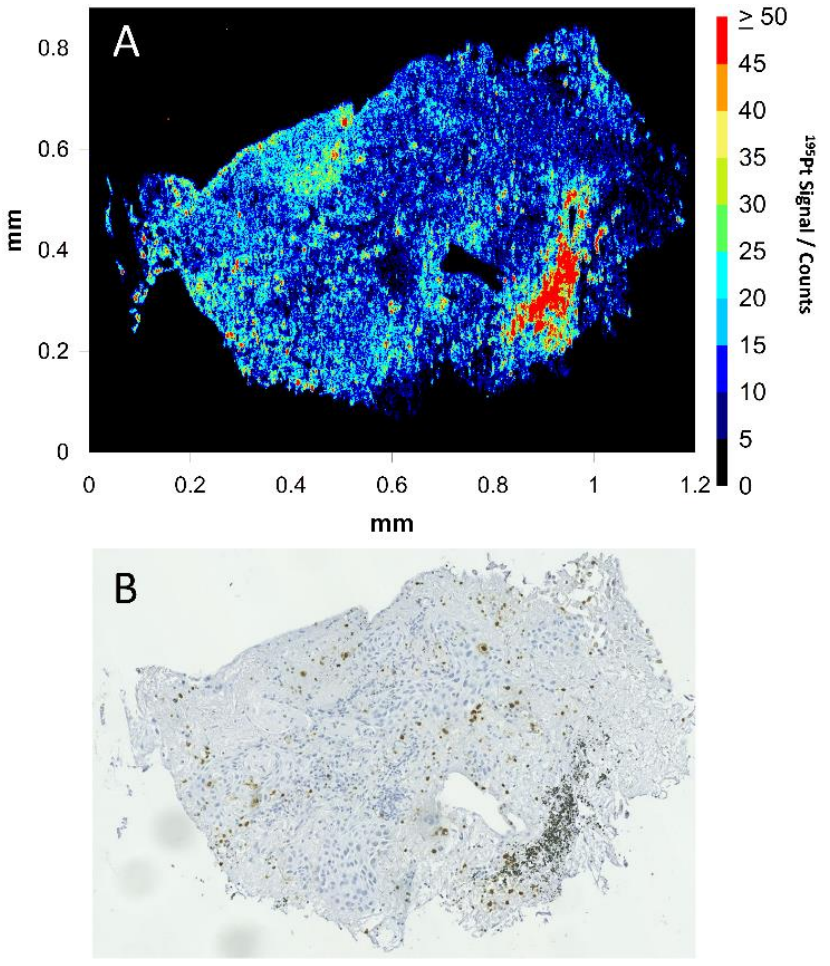

Figure 3. Explant dosed with $1 \mu \mathrm{M}$ cisplatin from a case showing dose dependent resistance. Figure B displaying cPARP activity (brown) also shows carbon deposits (small black spots) visible in the lower right of the tissue. The same location in figure A displays a strong platinum signature in the region enriched with carbon particles.

suggests the carbonaceous regions do not contain platinum before treatment with cisplatin.

An alternative hypothesis was that a matrix effect may be responsible for artificial enhancement of the Pt signal in regions containing carbon. The presence of carbon is known to enhance the signal for some difficult to ionize elements, such as As and Se, which has been attributed to charge transfer reactions where $\mathrm{C}^{+}$ species can pass charge over to the element of interest during ionization within the plasma. ${ }^{43-45}$ An enhancement effect for $\mathrm{Pt}$ has not been experimentally observed in previous studies on coexisting carbon. ${ }^{46,47}$ However, it is possible that the latest generation of LA systems may introduce additional ionization effects that were not evident with the older technology. These new systems are designed to provide rapid transit of material through the plasma and they confine material to the central channel to improve transport efficiency through the cones. This shorter time for ionization could potentially reduce the ionization of elements that would typically not be susceptible to enhancement effects (Pt is typically $62 \%$ ionized $^{46}$ ). To investigate this, a series of piezoelectric droplet-based Pt standards were prepared with varying levels of a carbon solution. The approach provides reproducible, picolitre sized droplets that can be imaged rapidly to provide a model of matrix effects. The resulting data revealed no discernable increase in total Pt signal with increasing carbon content, in the range of 0 to $500 \mathrm{ppm}$ carbon (Supporting Information). The above data indicated that ionization effects are unlikely to be responsible for the C-Pt correlation, but this does not eliminate the possibility of a matrix effect at the sampling stage. For example, the presence of carbon particulate, rather than dissolved carbon, at the target site, could plausibly increase coupling of the laser with 

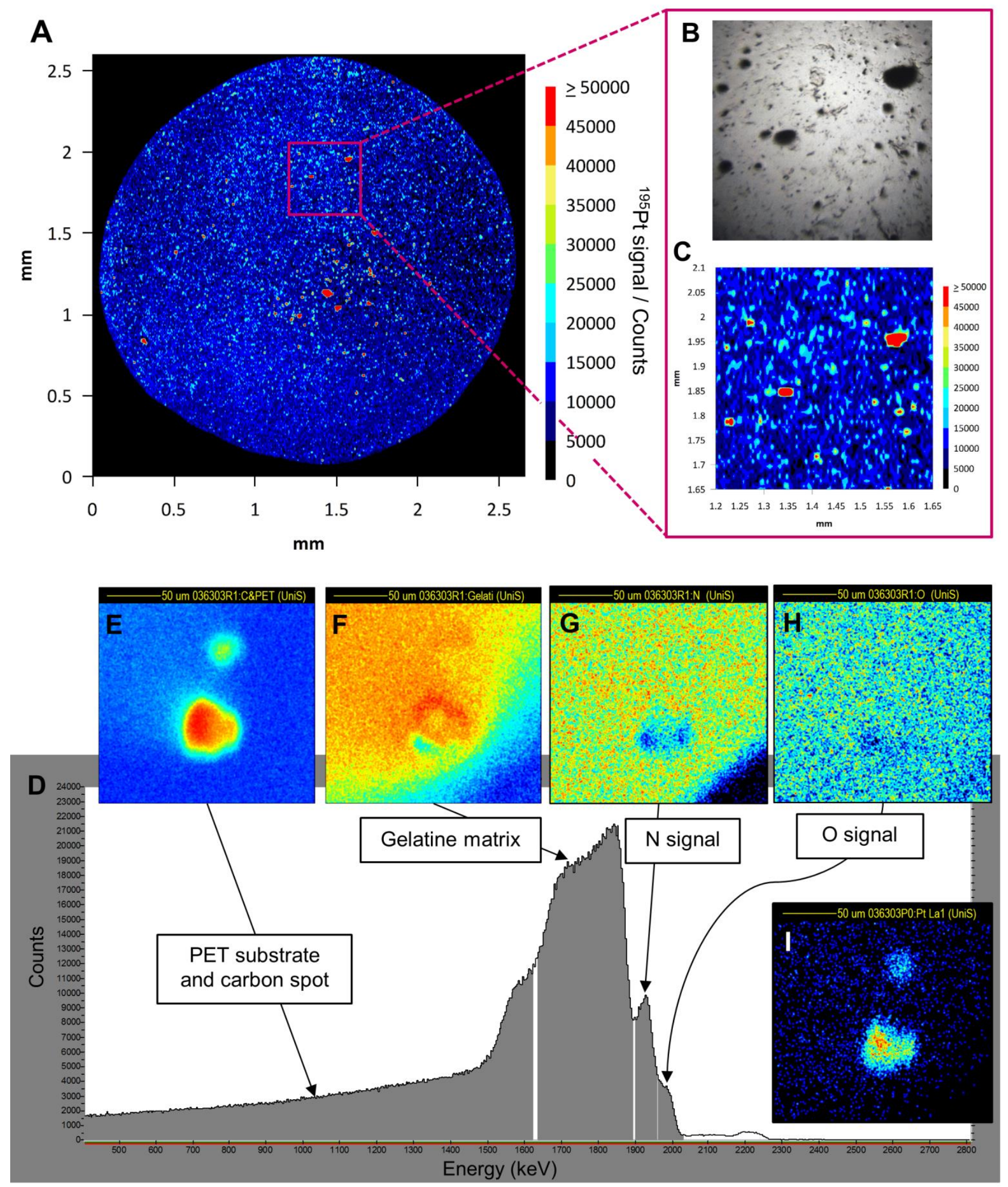

Figure 4. Analysis of platinum in a gelatine droplet, incubated for 24 hours with $50 \mu \mathrm{g} \mathrm{mL} \mathrm{Lt}^{-1} \mathrm{Pt}$ and $1 \mathrm{mg}$ of ground charcoal. Image A displays the Pt signal following LA-ICP-MS imaging of the whole droplet. Image $\mathrm{C}$ is a magnification of the highlighted region in A, with figure B showing the corresponding microscope perspective of this region. The black spots visible in Image B are finely ground charcoal fragments. Image D is a PIXE-EBS spectrum, which shows the difference between the gelatine matrix and the carbon spot/PET substrate. Insets E-H show the distribution of carbon from the PET slide, carbon from the gelatine matrix, nitrogen and oxygen across the sampled region. The corresponding platinum image is shown in inset I. This confirms that the signals measured for Pt derive mostly from the carbon spot and not the gelatine matrix. 
the sample, and hence increase the mass of material ablated. To investigate this possibility, a platinum standard solution of $50 \mu \mathrm{g}$ $\mathrm{mL}^{-1}$ was incubated in gelatine for 24 hours with $1 \mathrm{mg}$ finely ground charcoal. The aforementioned piezo-electric droplet generator approach could not be used with carbon particulate due to the small diameter of the nozzle, thus a standard pipette was used to dispense the droplet. Imaging of the dried droplet revealed regions of high platinum signal that could be directly correlated to the location of carbon deposits in the gelatine (Figure 4).

To determine whether this was a matrix effect, complementary analysis using a technique that employs a different sampling and analysis mechanism was required. IBA uses a $\mathrm{MeV}$ ion beam, rather than a laser, to sample the target. For PIXE, the signal comes from X-rays emitted by electron transitions into inner shell vacancies. The elemental components of the sample can be identified from their unique emission spectra, with detection limits typically in the parts per million range. Importantly, because the signal comes from inner shell electrons, the $\mathrm{X}$-ray production cross section does not depend on the chemical state of the atom. ${ }^{48,49}$ Due to the beryllium window fitted on the X-ray detector, elements lighter than $\mathrm{Na}$ were not detectable via the PIXE setup used in this work. However, lighter elements like $\mathrm{C}, \mathrm{N}$ and $\mathrm{O}$ can be identified by the simultaneous elastic backscattering spectrometry (EBS) measurements. Figure 4 shows the backscattered particle spectrum, collected simultaneously with the X-ray data, for the analysis of a region of $\mathrm{Pt}$ spiked gelatin that contained carbon particulate. The co-localization of carbon and platinum over the $200 \times 200 \mu \mathrm{m}$ area sampled is also shown. Analysis of a control sample confirmed that the carbon particulate did not contain detectable Pt prior to exposure to the spiked gelatine (Supporting Information). It is also known that X-ray spectra can be affected by absorption when there is a change in the average $\mathrm{Z}$ of the matrix. Here, the change in matrix from gelatine to a carbon particle has an effect on the carbon to oxygen ratio of the matrix (as demonstrated by the backscattered particle spectra shown in Figure 4). A simulation of the X-ray absorption (see Supporting Information) shows how a change in matrix from pure $\mathrm{O}$ to pure $\mathrm{C}$ would have no impact on the measured Pt L X-ray intensity.

These complementary measurements validate the findings of the LA-ICP-MS data and indicate that carbon deposits in the tissue may actively sequester platinum. If this theory is correct, this could potentially impact movement of cisplatin through tissues, with significant implications for the treatment of patients who have large quantities of carbon deposits in their lungs.

\section{CONCLUSIONS}

Cisplatin penetration in tissues of different phenotypes can be accurately predicted and observed using LA-ICP-MS imaging as a screening tool. With only a small proportion of NSCLC patients benefitting from receiving cisplatin treatment, the explant approach could strengthen clinical decision making by pre-screening patients in advance of their treatment. This may potentially reduce unnecessary side-effects in patients with cisplatin resistant tumours, accelerating the provision of alternative treatment strategies for these patients, as well as identifying patients with sensitive tumours that may otherwise not be routinely offered the drug. The high-resolution imaging approach revealed an association between Pt distribution and carbon deposits in the tissue, which was not observed in an earlier low-resolution study. Carbon deposits found in lung tissue may be detrimental to the movement and therefore efficacy of cisplatin treatment. A large proportion of lung cancer patients have a history of smoking, which increases the likelihood of finding carbon deposition in their lungs. Thus, the finding warrants further investigation to understand the potential impact of carbon deposition on the performance of cisplatin and other platinum-based drugs in NSCLC treatment.
The use of a low dispersion ablation cell in conjunction with the Dual Concentric Injector has dramatically increased the resolution and speed of analysis possible with LA-ICP-MS, with high resolution analysis accurately reflecting observations that have been made using traditional clinical screening methods such as histology and IHC. Improvements in the acquisition speed are also a significant factor in making LA-ICP-MS a more realistic and accessible tool for future screening approaches for cisplatin and other metallo-drugs. It is noted that the standards used as a model of matrix effects could also be used to provide a quantitative result in clinical studies of metallo-drug uptake. Orthogonal techniques were used to explore the origins of the carbon-platinum association in the data, with ion beam analysis proving a useful approach to validate the conclusions of the LA-ICP-MS experiments. With the relatively recent introduction of low-dispersion LA interfaces, very few publications thus far have considered how this substantial change to the sample introduction method could cause effects downstream in the plasma. The availability of suitable complementary analysis methods may prove vital to the investigation of changes in ionization properties, as these systems begin to gain popularity.

\section{ASSOCIATED CONTENT}

\section{Supporting Information}

The Supporting Information is available free of charge on the ACS Publications website. Schematic of the instrumentation, pulse response profiles, LA-ICP-MS and histological data from further sensitive, dose dependent and resistant cases, imaging of $\mathrm{Pt}+\mathrm{C}$ spiked gelatine droplets, PIXE spectra (PDF)

\section{AUTHOR INFORMATION}

\section{Corresponding Author \\ * E-mail: A.J.Managh@lboro.ac.uk}

\section{ACKNOWLEDGMENTS}

C. Greenhalgh would like to thank Loughborough University for the provision of a funded $\mathrm{PhD}$ studentship. Preparation of explants was supported by a Medical Research Council (MRC) Doctoral Training Grant to E. Karekla, the MRC Toxicology Unit (MC A/600), and the Leicester Experimental Cancer Medicine Centre (C325/A15575 Cancer Research UK/UK Department of Health). C. Pritchard was supported by a Royal Society- Wolfson merit award. Access to the UK National Ion beam Centre was provided through an EPSRC pump primer grant (project 579). The authors would also like to thank Barry Sharp for insightful discussions during the preparation of this manuscript.

\section{REFERENCES}

(1) Dasari, S.; Tchounwou, P. B. Cisplatin in cancer therapy: molecular mechanisms of action; Eur. J. Pharmacol., 2014, 740, 364-378.

(2) Pignon, J.-P.; Tribodet, H.; Scagliotti, G. V.; Douillard, J.-Y.; Shepherd, F. A.; Stephens, R. J.; Dunant, A.; Torri, V.; Rosell, R.; Seymour, L.; Spiro, S. G.; Rolland, E.; Fossati, R.; Aubert, D.; Ding, K.; Waller, D.; Chevalier, T. L. Lung Adjuvant Cisplatin Evaluation: A Pooled Analysis by the LACE Collaborative Group; J. Clin. Oncol., 2008, 26, 3552-3559.

(3) Galluzzi, L.; Senovilla, L.; Vitale, I.; Michels, J.; Martins, I.; Kepp, O.; Castedo, M.; Kroemer, G. Molecular mechanisms of cisplatin resistance; Oncogene, 2012, 31, 1869-1883.

(4) Klein, A. V.; Hambley, T. W. Platinum Drug Distribution in Cancer Cells and Tumors; Chem. Rev., 2009, 109, 4911-4920.

(5) Theiner, S.; Schreiber-Brynzak, E.; Jakupec, M. A.; Galanski, M.; Koellensperger, G.; Keppler, B. K. LA-ICP-MS imaging in multicellular tumor spheroids - a novel tool in the preclinical development of metal-based anticancer drugs; Metallomics, 2016, 8, 398-402. 
(6) Corte Rodríguez, M.; Álvarez-Fernández García, R.; Blanco, E.; Bettmer, J.; Montes-Bayón, M. Quantitative Evaluation of Cisplatin Uptake in Sensitive and Resistant Individual Cells by Single-Cell ICP-MS (SC-ICP-MS); Anal. Chem., 2017, 89, 11491-11497.

(7) Siolas, D.; Hannon, G. J. Patient-Derived Tumor Xenografts: Transforming Clinical Samples into Mouse Models; J. Cancer Res., 2013, 73, 5315-5319.

(8) Karekla, E.; Liao, W.-J.; Sharp, B.; Pugh, J.; Reid, H.; Quesne, J. L.; Moore, D.; Pritchard, C.; MacFarlane, M.; Pringle, J. H. Ex Vivo Explant Cultures of Non-Small Cell Lung Carcinoma Enable Evaluation of Primary Tumor Responses to Anticancer Therapy; Cancer Res., 2017, 77, 2029-2039.

(9) Powley, I. R.; Patel, M.; Miles, G.; Pringle, H.; Howells, L.; Thomas, A.; Kettleborough, C.; Bryans, J.; Hammonds, T.; MacFarlane, M.; Pritchard, C. Patient-derived explants (PDEs) as a powerful preclinical platform for anti-cancer drug and biomarker discovery; Br. J. Cancer, 2020, 122, 735-744.

(10) Pozebon, D.; Scheffler, G. L.; Dressler, V. L. Recent applications of laser ablation inductively coupled plasma mass spectrometry (LA-ICP-MS) for biological sample analysis: a follow-up review; $J$. Anal. At. Spectrom., 2017, 32, 890-919.

(11) Egger, A. E.; Theiner, S.; Kornauth, C.; Heffeter, P.; Berger, W.; Keppler, B. K.; Hartinger, C. G. Quantitative bioimaging by LAICP-MS: a methodological study on the distribution of $\mathrm{Pt}$ and $\mathrm{Ru}$ in viscera originating from cisplatin- and KP1339-treated mice; Metallomics, 2014, 6, 1616-1625.

(12) Moreno-Gordaliza, E.; Giesen, C.; Lazaro, A.; Esteban-Fernandez, D.; Humanes, B.; Canas, B.; Panne, U.; Tejedor, A.; Jakubowski, N.; Gomez-Gomez, M. M. Elemental Bioimaging in Kidney by LAICP-MS As a Tool to Study Nephrotoxicity and Renal Protective Strategies in Cisplatin Therapies; Anal. Chem., 2011, 83, 79337940.

(13) Reifschneider, O.; Wehe, C. A.; Raj, I.; Ehmcke, J.; Ciarimboli, G.; Sperling, M.; Karst, U. Quantitative bioimaging of platinum in polymer embedded mouse organs using laser ablation ICP-MS; Metallomics, 2013, 5, 1440-1447.

(14) Zoriy, M.; Matusch, A.; Spruss, T.; Becker, J. S. Laser ablation inductively coupled plasma mass spectrometry for imaging of copper, zinc, and platinum in thin sections of a kidney from a mouse treated with cis-platin; Int. J. Mass Spectrom., 2007, 260, 102-106.

(15) Köppen, C.; Reifschneider, O.; Castanheira, I.; Sperling, M.; Karst, U.; Ciarimboli, G. Quantitative imaging of platinum based on laser ablation-inductively coupled plasma-mass spectrometry to investigate toxic side effects of cisplatin; Metallomics, 2015, 7, 1595-1603.

(16) Gholap, D.; Verhulst, J.; Ceelen, W.; Vanhaecke, F. Use of pneumatic nebulization and laser ablation-inductively coupled plasma-mass spectrometry to study the distribution and bioavailability of an intraperitoneally administered Pt-containing chemotherapeutic drug; Anal. Bioanal. Chem, 2012, 402, 21212129.

(17) Bianga, J.; Bouslimani, A.; Bec, N.; Quenet, F.; Mounicou, S.; Szpunar, J.; Bouyssiere, B.; Lobinski, R.; Larroque, C. Complementarity of MALDI and LA ICP mass spectrometry for platinum anticancer imaging in human tumor; Metallomics, 2014, 6 , 1382-1386.

(18) Bonta, M.; Lohninger, H.; Laszlo, V.; Hegedus, B.; Limbeck, A. Quantitative LA-ICP-MS imaging of platinum in chemotherapy treated human malignant pleural mesothelioma samples using printed patterns as standard; J. Anal. At. Spectrom., 2014, 29, 21592167.

(19) Egger, A. E.; Kornauth, C.; Haslik, W.; Hann, S.; Theiner, S.; Bayer, G.; Hartinger, C. G.; Keppler, B. K.; Pluschnig, U.; Mader, R. M. Extravasation of Pt-based chemotherapeutics - bioimaging of their distribution in resectates using laser ablation-inductively coupled plasma-mass spectrometry (LA-ICP-MS); Metallomics, 2015, 7, 508-515.

(20) Pozebon, D.; Dressler, V. L.; Matusch, A.; Becker, J. S. Monitoring of platinum in a single hair by laser ablation inductively coupled plasma mass spectrometry (LA-ICP-MS) after cisplatin; Int. J. Mass Spectrom., 2008, 272, 57-62.

(21) Niehoff, A.-C.; Grünebaum, J.; Moosmann, A.; Mulac, D.; Söbbing, J.; Niehaus, R.; Buchholz, R.; Kröger, S.; Wiehe, A.; Wagner, S.; Sperling, M.; von Briesen, H.; Langer, K.; Karst, U.
Quantitative bioimaging of platinum group elements in tumor spheroids; Anal. Chim. Acta, 2016, 938, 106-113.

(22) Lee, R. F. S.; Theiner, S.; Meibom, A.; Koellensperger, G.; Keppler, B. K.; Dyson, P. J. Application of imaging mass spectrometry approaches to facilitate metal-based anticancer drug research; Metallomics, 2017, 9, 365-381.

(23) Douglas, D. N.; Managh, A. J.; Reid, H. J.; Sharp, B. L. HighSpeed, Integrated Ablation Cell and Dual Concentric Injector Plasma Torch for Laser Ablation-Inductively Coupled Plasma Mass Spectrometry; Anal. Chem., 2015, 87, 11285-11294.

(24) Burger, M.; Gundlach-Graham, A.; Allner, S.; Schwarz, G.; Wang, H. A. O.; Gyr, L.; Burgener, S.; Hattendorf, B.; Grolimund, D.; Günther, D. High-Speed, High-Resolution, Multielemental LAICP-TOFMS Imaging: Part II. Critical Evaluation of Quantitative Three-Dimensional Imaging of Major, Minor, and Trace Elements in Geological Samples; Anal. Chem., 2015, 87, 8259-8267.

(25) Van Malderen, S. J. M.; van Elteren, J. T.; Vanhaecke, F. Development of a fast laser ablation-inductively coupled plasmamass spectrometry cell for sub- $\mu \mathrm{m}$ scanning of layered materials; $J$. Anal. At. Spectrom., 2015, 30, 119-125.

(26) Van Malderen, S. J. M.; Managh, A. J.; Sharp, B. L.; Vanhaecke, F. Recent developments in the design of rapid response cells for laser ablation-inductively coupled plasma-mass spectrometry and their impact on bioimaging applications; J. Anal. At. Spectrom., 2016, $31,423-439$.

(27) Craig, G.; Managh, A. J.; Stremtan, C.; Lloyd, N. S.; Horstwood, M. S. A. Doubling Sensitivity in Multicollector ICPMS Using High-Efficiency, Rapid Response Laser Ablation Technology; Anal. Chem., 2018, 90, 11564-11571.

(28) Van Acker, T.; Van Malderen, S. J. M.; Van Heerden, M.; McDuffie, J. E.; Cuyckens, F.; Vanhaecke, F. High-resolution laser ablation-inductively coupled plasma-mass spectrometry imaging of cisplatin-induced nephrotoxic side effects; Anal. Chim. Acta, 2016, 945, 23-30.

(29) Theiner, S.; Van Malderen, S. J. M.; Van Acker, T.; Legin, A.; Keppler, B. K.; Vanhaecke, F.; Koellensperger, G. Fast HighResolution Laser Ablation-Inductively Coupled Plasma Mass Spectrometry Imaging of the Distribution of Platinum-Based Anticancer Compounds in Multicellular Tumor Spheroids; Anal. Chem., 2017, 89, 12641-12645.

(30) Bailey, M. J.; Coe, S.; Grant, D. M.; Grime, G. W.; Jeynes, C. Accurate determination of the Ca:P ratio in rough hydroxyapatite samples by SEM-EDS, PIXE and RBS-a comparative study; $X$ Ray Spectrom., 2009, 38, 343-347.

(31) Jeynes, J. C. G.; Bailey, M. J.; Coley, H.; Kirkby, K. J.; Jeynes, C. Microbeam PIXE analysis of platinum resistant and sensitive ovarian cancer cells; Nucl. Instrum. Methods Phys. Res. B, 2010 , 268, 2168-2171.

(32) Zheng, P.-P.; van der Weiden, M.; Kros, J. M. Fast Tracking of CoLocalization of Multiple Markers by Using the Nanozoomer Slide Scanner and NDPViewer; J. Cell Physiol., 2014, 229, 967-973.

(33) Bankhead, P.; Loughrey, M. B.; Fernández, J. A.; Dombrowski, Y.; McArt, D. G.; Dunne, P. D.; McQuaid, S.; Gray, R. T.; Murray, L. J.; Coleman, H. G.; James, J. A.; Salto-Tellez, M.; Hamilton, P. W. QuPath: Open source software for digital pathology image analysis; Sci. Rep., 2017, 7, 16878.

(34) Arakawa, A.; Jakubowski, N.; Flemig, S.; Koellensperger, G.; Rusz, M.; Iwahata, D.; Traub, H.; Hirata, T. High-resolution laser ablation inductively coupled plasma mass spectrometry used to study transport of metallic nanoparticles through collagen-rich microstructures in fibroblast multicellular spheroids; Anal. Bioanal. Chem., 2019, 411, 3497-3506.

(35) Managh, A. J.; Douglas, D. N.; Makella Cowen, K.; Reid, H. J.; Sharp, B. L. Acquisition of fast transient signals in ICP-MS with enhanced time resolution; J. Anal. At. Spectrom., 2016, 31, 16881692.

(36) Managh, A. J.; Reid, P. A new freeware tool for image processing and its application to high speed LA-ICP-MS imaging; J. Anal. At. Spectrom., 2019, 34, 1369-1373.

(37) Westerhausen, M. T.; Bishop, D. P.; Dowd, A.; Wanagat, J.; Cole, N.; Doble, P. A. Super-Resolution Reconstruction for Two- and Three-Dimensional LA-ICP-MS Bioimaging; Anal. Chem., 2019, 91, 14879-14886.

(38) Bonta, M.; Török, S.; Hegedus, B.; Döme, B.; Limbeck, A. A comparison of sample preparation strategies for biological tissues 
and subsequent trace element analysis using LA-ICP-MS; Anal. Bioanal. Chem., 2017, 409, 1805-1814.

(39) Makovec, T. Cisplatin and beyond: molecular mechanisms of action and drug resistance development in cancer chemotherapy; Radiol. Oncol., 2019, 53, 148-158.

(40) Takano, A. P. C.; Justo, L. T.; dos Santos, N. V.; Marquezini, M. V.; de André, P. A.; da Rocha, F. M. M.; Pasqualucci, C. A.; Barrozo, L. V.; Singer, J. M.; De André, C. D. S.; Saldiva, P. H. N.; Veras, M. M. Pleural anthracosis as an indicator of lifetime exposure to urban air pollution: An autopsy-based study in Sao Paulo; Environ. Res., 2019, 173, 23-32.

(41) Prichard, H. M.; Fisher, P. C. Identification of Platinum and Palladium Particles Emitted from Vehicles and Dispersed into the Surface Environment; Environ Sci. Technol., 2012, 46, 3149-3154.

(42) Moldovan, M.; Palacios, M. A.; Gómez, M. M.; Morrison, G.; Rauch, S.; McLeod, C.; Ma, R.; Caroli, S.; Alimonti, A.; Petrucci, F.; Bocca, B.; Schramel, P.; Zischka, M.; Pettersson, C.; Wass, U.; Luna, M.; Saenz, J. C.; Santamaría, J. Environmental risk of particulate and soluble platinum group elements released from gasoline and diesel engine catalytic converters; Sci. Total Environ. 2002, 296, 199-208.

(43) Larsen, E. H.; Stürup, S. Carbon-enhanced inductively coupled plasma mass spectrometric detection of arsenic and selenium and its application to arsenic speciation; J. Anal. At. Spectrom., 1994, 9 , 1099-1105.

(44) Pettine, M.; Casentini, B.; Mastroianni, D.; Capri, S. Dissolved inorganic carbon effect in the determination of arsenic and chromium in mineral waters by inductively coupled plasma-mass spectrometry; Anal. Chim. Acta, 2007, 599, 191-198.

(45) Hu, Z.; Hu, S.; Gao, S.; Liu, Y.; Lin, S. Volatile organic solventinduced signal enhancements in inductively coupled plasma-mass spectrometry: a case study of methanol and acetone; Spectrochim. Acta Part B, 2004, 59, 1463-1470.

(46) Nakazawa, T.; Suzuki, D.; Sakuma, H.; Furuta, N. Comparison of signal enhancement by co-existing carbon and by co-existing bromine in inductively coupled plasma mass spectrometry; J. Anal. At. Spectrom., 2014, 29, 1299-1305.

(47) Grindlay, G.; Mora, J.; de Loos-Vollebregt, M.; Vanhaecke, F. A systematic study on the influence of carbon on the behavior of hardto-ionize elements in inductively coupled plasma-mass spectrometry; Spectrochim. Acta Part B, 2013, 86, 42-49.

(48) Jeynes, C.; Bailey, M. J.; Bright, N. J.; Christopher, M. E.; Grime, G. W.; Jones, B. N.; Palitsin, V. V.; Webb, R. P. "Total IBA" Where are we?; Nucl. Instrum. Methods Phys. Res. B, 2012, 271, 107-118.

(49) Jeynes, C.; Colaux, J. L. Thin film depth profiling by ion beam analysis; Analyst, 2016, 141, 5944-5985.

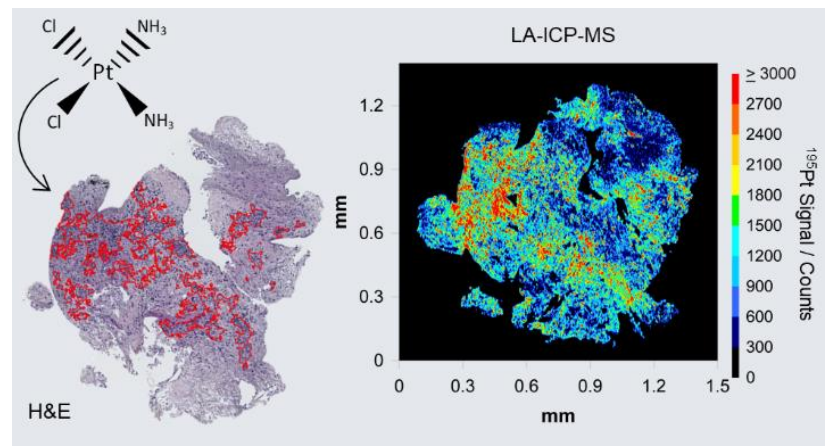

Table of Contents artwork 